\title{
Home-based carer-assisted therapy for people with stroke: findings from a randomised controlled trial
}

\author{
Nor Azlin Mohd Nordin ${ }^{1,2^{*}}$, Noor Azah Aziz ${ }^{3}$, Saperi Sulong ${ }^{4}$, Syed Mohamed Aljunid ${ }^{2}$ \\ From 6th Postgraduate Forum on Health Systems and Policies \\ Melaka, Malaysia. 21-22 May 2012
}

\section{Background}

The benefits of engaging carers in the rehabilitation of people with stroke have not been well-researched despite emphasis on shared responsibility between healthcare providers and the stroke patient's family. This study aimed to assess the effectiveness of a task-oriented training assisted by carer for stroke patients living at home following hospital rehabilitation.

\section{Materials and methods}

A single-blinded randomised controlled trial was conducted on 91 stroke patients. In all, 76.5\% males with mean age of $58.9 \pm 10.6$ years and median stroke duration of 13.0 months (range 6-84) completed intensive rehabilitation at a tertiary hospital. The control group received outpatient group exercise led by therapists while the experimental group was assigned to a home-based familyassisted task-oriented training. Primary outcomes were mobility (Rivermead Mobility Scale), balance (Berg's Balance Scale), lower limb strength (5-Times-Sit-to-Stand Test) and gait speed. Secondary outcome was healthrelated quality of life as measured using EQ5D-Visual analogue Scale. All assessments were carried out at baseline and at week twelve of intervention. An intention-totreat analysis was used to evaluate outcome of the interventions.

\section{Results}

No statistical differences were found between the experimental and the control group in all outcomes (all $\mathrm{p}>0.25$ ) at completion of the trial. Both groups improved significantly in all the measures of function; mobility $(\mathrm{p}<0.01)$, balance $(\mathrm{p}<0.01)$, lower limb strength $(\mathrm{p}<0.01)$, gait speed $(p<0.05)$, and in the quality of life score $(\mathrm{p}<0.05)$. The study participants showed meaningful progress in gait speed (mean gain $>8.0 \mathrm{~m} / \mathrm{min}$ ) after twelve weeks of intervention irrespective of the therapy group.

\section{Conclusion}

The home-based carer-assisted therapy is as effective as the outpatient therapist-led training in improving poststroke functions and quality of life. The programme may be considered as part of a discharge or long-term care plan for stroke patients following hospital rehabilitation.

\section{Author details}

${ }^{1}$ Faculty of Health Sciences, Universiti Kebangsaan Malaysia, Jalan Raja Muda Abdul Aziz, 50300 Kuala Lumpur, Malaysia. ²United Nations UniversityInternational Institute for Global Health, Universiti Kebangsaan Malaysia Medical Centre, Jalan Yaacob Latiff, 56000 Kuala Lumpur, Malaysia.

${ }^{3}$ Department of Family Medicine, Universiti Kebangsaan Malaysia Medical Centre, Jalan Yaacob Latiff, 56000 Kuala Lumpur, Malaysia. ${ }^{4}$ Department of Health Information, Universiti Kebangsaan Malaysia Medical Centre, Jalan Yaacob Latiff, 56000 Kuala Lumpur, Malaysia.

Published: 27 November 2012

\section{doi:10.1186/1471-2458-12-S2-A2}

Cite this article as: Nordin et al:: Home-based carer-assisted therapy for people with stroke: findings from a randomised controlled trial. BMC Public Health 2012 12(Suppl 2):A2.

${ }^{1}$ Faculty of Health Sciences, Universiti Kebangsaan Malaysia, Jalan Raja Muda Abdul Aziz, 50300 Kuala Lumpur, Malaysia

Full list of author information is available at the end of the article

(c) 2012 Nordin et al; licensee BioMed Central Ltd. This is an Open Access article distributed under the terms of the Creative Commons 